\title{
Effects of acute and chronic inflammation on proteins involved in duodenal iron absorption in mice: a time-course study
}

\author{
Abitha Sukumaran ${ }^{1}$, Joe Varghese ${ }^{1}$, Jesintha Tamilselvan ${ }^{1}$, Visalakshi Jeyaseelan ${ }^{2}$, Thenmozhi Mani ${ }^{2}$, \\ Robert James Simpson ${ }^{3}$, Andrew Tristan McKie $^{3}$ and Molly Jacob ${ }^{1 *}$ \\ ${ }^{1}$ Department of Biochemistry, Christian Medical College, Vellore, Tamil Nadu, India \\ ${ }^{2}$ Department of Biostatistics, Christian Medical College, Vellore, Tamil Nadu, India \\ ${ }^{3}$ Nutritional Sciences Division, King's College London, London SE1 9NH, UK
}

(Submitted 21 July 2011 - Final revision received 17 December 2011 - Accepted 11 January 2012 - First published online 24 February 2012)

\begin{abstract}
In order to understand better the molecular mechanisms involved in the pathogenesis of anaemia of inflammation, we carried out a timecourse study on the effects of turpentine-induced acute and chronic inflammation on duodenal proteins involved in Fe absorption in mice. Expression levels of these proteins and hepatic hepcidin and serum Fe levels were determined in inflamed mice. In acutely inflamed mice, significantly increased expression of ferritin was the earliest change observed, followed by decreased divalent metal transporter 1 expression in the duodenum and increased hepcidin expression in the liver. Ferroportin expression increased subsequently, despite high levels of hepcidin. Hypoferraemia, which developed at early time periods studied, was followed by increased serum Fe levels at later points. The present results thus show that acute inflammation induced several changes in the expression of proteins involved in duodenal Fe absorption, contributing to the development of hypoferraemia. Resolution of inflammation caused attenuation of many of these effects. Effects in chronically inflamed mice were less consistent. The present results also suggest that inflammation-induced increases in ferritin appeared to override the effects of hepcidin on the expression levels of ferroportin in enterocytes.
\end{abstract}

Key words: Duodenum: Hepcidin: Inflammation: Iron: Mice

Sequestration of Fe and subsequent hypoferraemia have been postulated to confer relative resistance to infection and alleviate the inflammatory condition ${ }^{(1)}$. Anaemia of inflammation (AI), also called anaemia of chronic disease, commonly develops in such a situation and also in conditions of trauma, malignancies or autoimmune diseases ${ }^{(2)}$. In AI, hypoferraemia occurs very quickly after the onset of inflammation, leading to the development of Fe-restricted erythropoiesis and anaemia $^{(3,4)}$. A liver-derived peptide, hepcidin, plays a central role in this process, as it restricts Fe entry into the circulation by reducing both intestinal Fe absorption and Fe release from monocytes/macrophages ${ }^{(3,5,6)}$. Hepcidin brings about these effects by binding to ferroportin, the only known Fe exporter in mammalian cells, found on the surface of enterocytes and macrophages, thereby promoting its internalisation and degradation $^{(7)}$. Inflammation has been shown to induce hepcidin expression in the liver; this has been shown to occur in response to the secretion of $\mathrm{IL}-6$, mainly by macrophages ${ }^{(3,8)}$. Studies have shown that pro-inflammatory cytokines affect many aspects of Fe homeostasis. They activate an endoplasmic reticulum stress response, which in turn modulates hepcidin expression during inflammatory responses ${ }^{(9,10)}$. Cytokines, such as TNF- $\alpha$, IL-1 or IL- 6 , also directly stimulate the transcription and translation of ferritin ${ }^{(11,12)}$. In addition, interferon- $\gamma$ and lipopolysaccharide have been reported to decrease ferroportin expression, independent of hepcidinmediated down-regulation, thereby reducing Fe release ${ }^{(13-15)}$.

Several studies ${ }^{(6,8,16-19)}$ have reported the effects of inflammation (produced by different agents) on proteins involved in $\mathrm{Fe}$ homeostasis. Hepcidin expression is elevated in mice treated with lipopolysaccharide or turpentine ${ }^{(6,8,17,18)}$. Sheikh et $a l{ }^{(18)}$ have shown that the acute-phase response modulated many of the genes involved in Fe homeostasis, namely divalent metal transporter 1 (DMT1), duodenal cytochrome b (dcytb), ferroportin, hephaestin, transferrin receptor 1 (TfR1), ferritin (heavy chain) and Fe regulatory proteins 1 and $2(\mathrm{IRP} 1 / 2)$ in various organs, including the small intestine ${ }^{(18)}$. However, most of these studies have studied

Abbreviations: AI, anaemia of inflammation; dcytb, duodenal cytochrome b; DMT1, divalent metal transporter 1; IRP1, iron regulatory protein 1; IRP2, iron regulatory protein 2 ; TfR 1 , transferrin receptor 1 .

*Corresponding author: Professor M. Jacob, fax +91 416 2262788, email mjacob@cmcvellore.ac.in 
the effects only up to $24 \mathrm{~h}$ after induction of inflammation. At the time that the present study was initiated, there were hardly any reports on the effects of longer-term inflammation on proteins involved in duodenal non-haem Fe absorption. Subsequently, a few studies have shown increases in the levels of hepcidin in chronic inflammation ${ }^{(16,19)}$. In addition, Theurl et al. ${ }^{(19)}$ have shown, in chronically inflamed arthritic rats, that such an increase was associated with a concomitant reduction in the expression of ferroportin in the duodenum and macrophages. Expression levels of DMT1 and TfR1 were, however, not significantly altered in these animals. There is little information on how chronic inflammation affects other proteins involved in $\mathrm{Fe}$ absorption and whether these effects differ from those seen in response to acute inflammation. The present study was a detailed time-course investigation to determine the effect of inflammation on proteins involved in duodenal $\mathrm{Fe}$ absorption, in an attempt to better understand the molecular events involved.

\section{Materials and methods}

Antibodies against ferroportin, dcytb and hephaestin were obtained from Alpha Diagnostic International, while those against DMT1, ferritin (heavy chain), TfR1, IRP1 and IRP2 were purchased from Santa Cruz. An antibody against $\beta$-actin, turpentine oil and TRI reagent was purchased from Sigma. Secondary antibodies and ECL West Dura substrate to develop Western blots were purchased from Thermo Scientific. ELISA kits for the estimation of IL- 6 were purchased from BD Biosciences. The reverse transcription core kit, quantitative PCR Mastermix Plus SYBR ${ }^{\circledR}$ Green No-ROX kit and genespecific primers used were obtained from Eurogentec. Absolute alcohol was purchased from Hayman. All chemicals used were of analytical grade.

\section{Animals}

Male Swiss albino mice (inbred strains obtained from the institutional animal house facility), which were 12 weeks of age and weighed between 25 and $35 \mathrm{~g}$, were used for all the experiments. Such mice have been used in many studies involving $\mathrm{Fe}^{(20-22)}$. Animals were allowed access to food and water ad libitum. They were fed standard rodent chow purchased from VRK Nutritional Solutions. The Fe content of the diet was $127 \mathrm{mg} / \mathrm{kg}$. Approval for use of the animals was obtained from the institutional animal ethics committee and was in accordance with the guidelines of the Committee for the Purpose of Control and Supervision of Experimentation on Animals, Government of India.

\section{Experimental protocol}

Acute inflammation. Acute inflammation was induced in mice by a single subcutaneous injection of turpentine oil $(0 \cdot 1 \mathrm{ml} / 20 \mathrm{~g}$ body weight $)$ into the inter-scapular fat pad of the animals ${ }^{(6)}$. Control animals received injections of sterile saline. The animals were killed at various time periods (ranging from $6 \mathrm{~h}$ to $7 \mathrm{~d}$ ) after the turpentine injection.
Chronic inflammation. Chronic inflammation was induced in a separate group of mice by subcutaneous injections of turpentine oil $(0 \cdot 1 \mathrm{ml} / 20 \mathrm{~g}$ body weight $)$ into the inter-scapular fat pad of the animals ${ }^{(6)}$. Control animals received injections of sterile saline. Mice received three injections of turpentine oil in all, given at weekly intervals, and were killed at various time periods ( $2 \mathrm{~d}$ and 1,2, 3 and 4 weeks) after the last injection.

When mice were killed, blood was collected by cardiac puncture and the duodenum and liver were harvested. The duodenum was opened along its anti-mesenteric border and the mucosa was scraped using a sterile glass slide. The duodenal mucosal scrapings and the liver were snap-frozen and stored at $-70^{\circ} \mathrm{C}$ until further use.

\section{Measurement of IL-6 in serum and duodenal homogenates}

Levels of IL-6 in serum and duodenal homogenates were determined in the experimental animals, using a commercially available ELISA kit (BD Bioscience). The assay was carried out according to the manufacturer's instructions.

\section{Isolation of total RNA, reverse transcription and real-time $P C R$ assays}

RNA was isolated from snap-frozen tissues of the control and inflamed animals using TRI reagent, according to the manufacturer's instructions. RNA $(1 \mu \mathrm{g})$ obtained was reverse transcribed into complementary DNA. The complementary DNA obtained was used for real-time PCR assays. The reaction conditions used are shown in Table S1 of the supplementary material, available online (http://www.journals.cambridge. org/bjn). Primer sequences used for the genes of interest were obtained from previously published work ${ }^{(23-26)}$. All reactions were carried out in triplicate. The relative expressions of the various genes of interest were determined in the control and inflamed animals by normalisation to $\beta$-actin, which was used as the housekeeping gene.

\section{Preparation of protein extracts for Western blotting}

Membrane and cytosolic protein extracts were prepared from duodenal tissue ${ }^{(27)}$. Protein concentrations in all the extracts were determined ${ }^{(28)}$. Membrane fractions were used for Western blotting of all proteins except ferritin (heavy chain), IRP1 and IRP2, for which cytosolic fractions were used. The protein extracts were subjected to SDS-PAGE using a $10 \%$ gel for DMT1, dcytb, ferroportin and TfR1. A gradient gel (between 4 and 20\%) was used to separate hephaestin, $8 \%$ gels for IRP1 and IRP2 and 12\% gels for ferritin. The proteins were transferred to polyvinylidene fluoride membranes at $25 \mathrm{~V}$ over $16 \mathrm{~h}$ for DMT1, ferroportin, dcytb, TfR1, IRP1 and IRP2, $20 \mathrm{~h}$ for hephaestin and $12 \mathrm{~h}$ for ferritin. The membranes were incubated with blocking solution (0.02\% Tween 20, $5 \%$ skimmed milk in PBS) for $2 \mathrm{~h}$ at room temperature, followed by incubation with primary antibodies for $16 \mathrm{~h}$ at $4^{\circ} \mathrm{C}$. The primary antibodies were used at the following dilutions: anti-DMT1 (1:300), anti-dcytb (1:200), anti-ferroportin 
(1:200), anti-hephaestin (1:200), anti-ferritin (1:300), anti-IRP1 (1:200), anti-IRP2 (1:100), anti-TfR1 (1:100) and anti- $\beta$-actin (1:5000). Incubation with primary antibodies was followed by incubation with peroxidase-labelled secondary antibodies (1:1000). The bands obtained were visualised by use of ECL West Dura substrate and quantified using a chemiluminescent imaging system (FluorChem ${ }^{\mathrm{TM}} \mathrm{SP}$; Alpha Innotech). The intensities of the bands of the proteins of interest were normalised with those of $\beta$-actin.

\section{Measurement of serum iron levels}

Serum levels of Fe were estimated as described previously ${ }^{(29)}$, with a few modifications. Briefly, $20 \mu \mathrm{l}$ of serum were incubated with $20 \mu \mathrm{l}$ of acid reagent $(3 \mathrm{M}-\mathrm{HCl}$ and $10 \% \mathrm{TCA})$ for $5 \mathrm{~min}$. An aliquot of the supernatant from this $(20 \mu \mathrm{l})$ was made up to $0.1 \mathrm{ml}$ with chromagen reagent ( $7 \mathrm{M}$-sodium acetate, $0.01 \%$ bathophenanthroline disulphonic acid and $0 \cdot 1 \%$ thioglycollic acid), and absorbance was measured at $540 \mathrm{~nm}$ using a microplate scanner, and compared with a standard solution of Fe treated identically.

\section{Statistical analysis}

Statistical analysis of data obtained was carried out using the SPSS software package, version 16. All parameters in the study were tested for normal distribution using the one-sample Kolmogorov-Smirnov test. They were analysed by ANOVA. A $P$ value of less than 0.05 was taken to indicate statistical significance in all cases.

\section{Results}

\section{Induction of inflammation}

Acute model. Serum IL-6 levels were increased significantly several fold between 6 and $48 \mathrm{~h}$ after the turpentine injections when compared with those in control mice. The levels tended to be higher than the control values at $3 \mathrm{~d}$ later as well, but the increases were not statistically significant (Fig. 1(A)). These results confirmed that inflammation had been successfully induced in the experimental animals.

Chronic model. Levels of IL-6 were found to progressively increase from $48 \mathrm{~h}$ after the last turpentine injection up to 2 weeks later. The increase at $48 \mathrm{~h}$ was not statistically significant but those at 1 and 2 weeks were significant (Fig. 1(B)). Subsequently, these levels fell close to the control levels. Levels of IL- 6 in the duodenal homogenates of inflamed mice were not significantly different from those in control mice at any of the time periods studied (Fig. 1(C)).

\section{Effects of acute inflammation on proteins of interest in the duodenum}

There were significant decreases in the protein levels of DMT1 in the acutely inflamed animals, at $24 \mathrm{~h}, 3$ and $5 \mathrm{~d}$ after the turpentine injection (Fig. 2(A) and (B)). Ferroportin expression
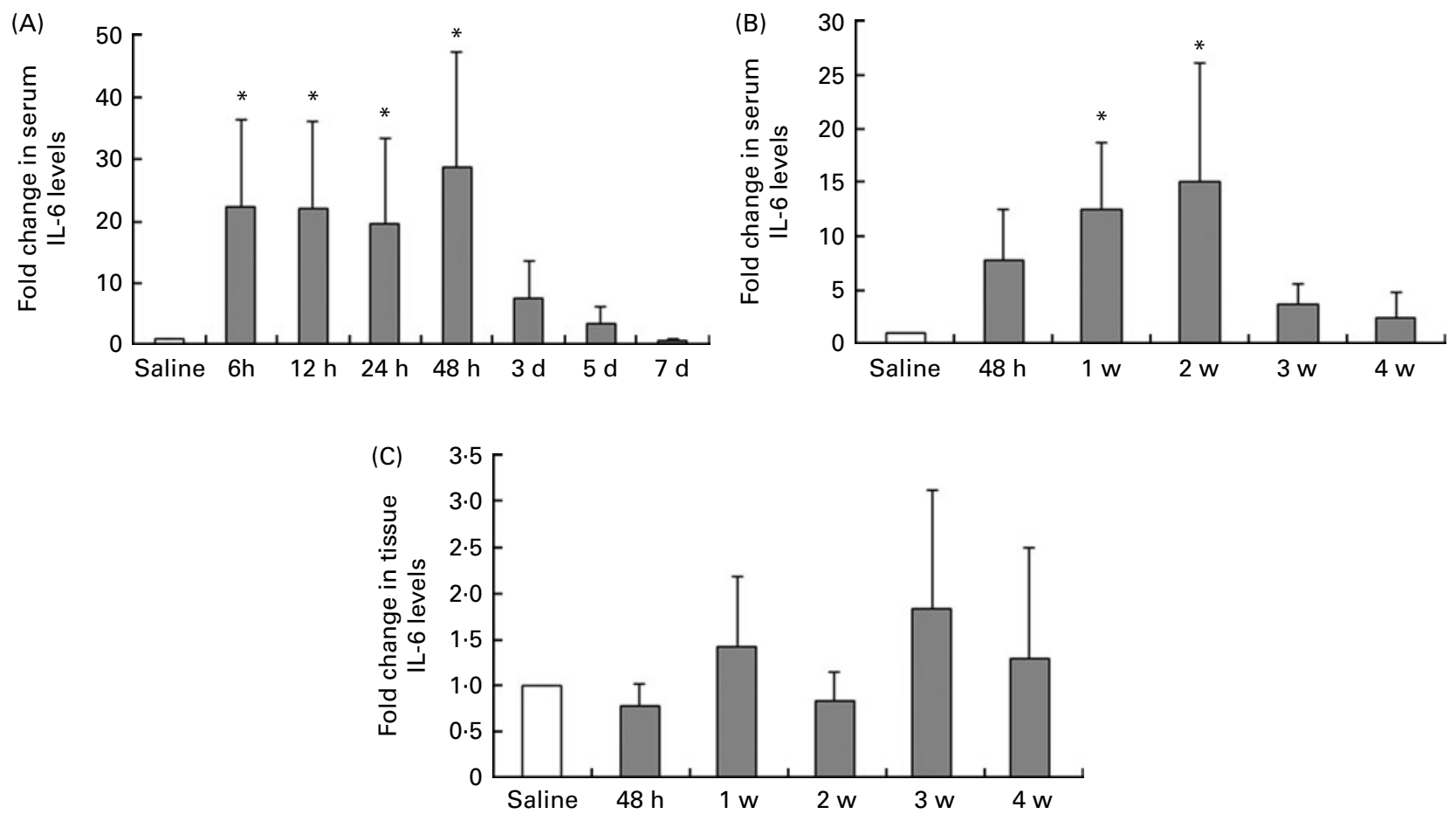

Fig. 1. Effect of inflammation on serum and duodenal IL-6 levels. Fold change in IL-6 levels in serum ((A) acute inflammation and (B) chronic inflammation) and duodenal homogenates $((C)$ chronic inflammation) from saline ( $\square)$ - and turpentine $(\square)$-treated mice ( $n$ 3-4 in all groups in each category) at various time periods of the study. Fold changes were calculated for each time period relative to corresponding saline-treated values. Data from saline-treated mice in each panel represent the mean of combined values from all the time periods of the study. Values are means, with standard deviations represented by vertical bars. ${ }^{\star}$ Mean values were significantly different $(P \leq 0.05)$. w, Weeks. 
was unaffected between 6 and $48 \mathrm{~h}$. This was followed by significantly higher expression levels between 3 and $7 \mathrm{~d}$ (Fig. 2(C) and (D)). Dcytb protein levels were significantly up-regulated between $24 \mathrm{~h}$ and $7 \mathrm{~d}$ (Fig. 2(E) and (F)). There were no consistent effects seen on the protein levels of hephaestin (Fig. 2(G) and (H)). Protein levels of ferritin (heavy chain) were significantly higher at $12 \mathrm{~h}$ and at 3 and $5 \mathrm{~d}$ (Fig. 2(I) and (J)). TfR1 protein in the duodenum was not detectable by Western blotting. However, this protein was detectable in liver homogenates from the same mice,

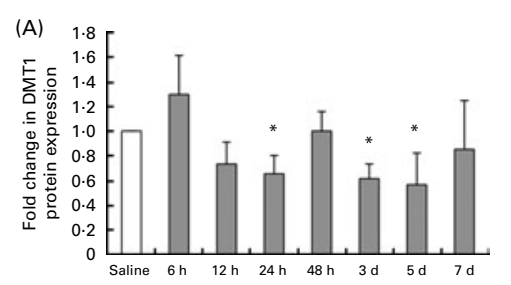

(B)

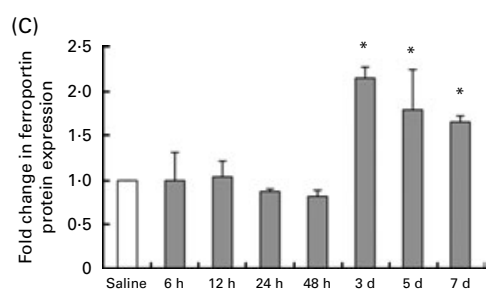

(D)
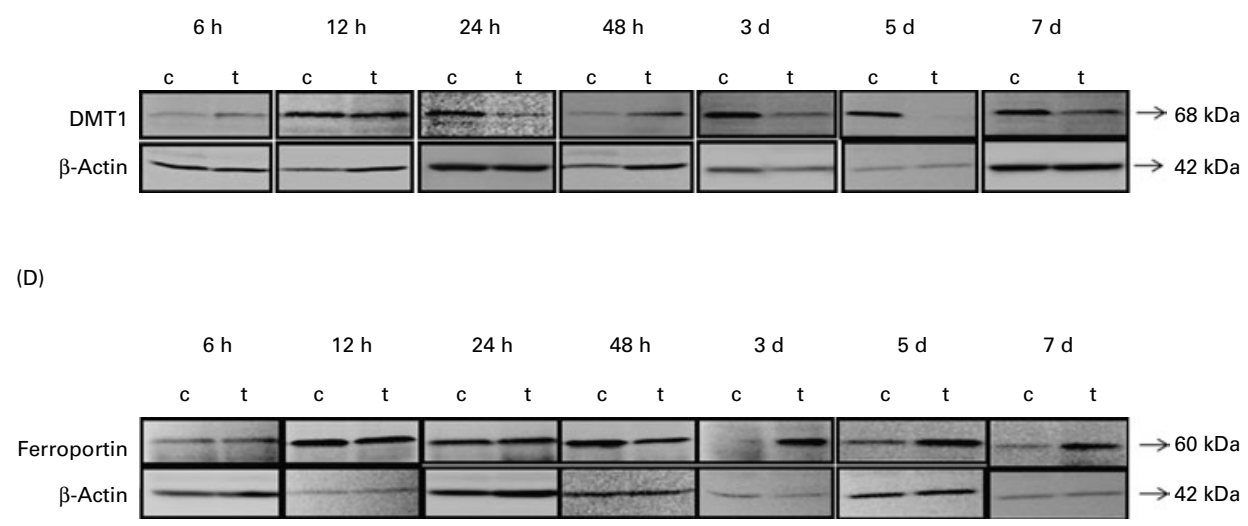

(F)
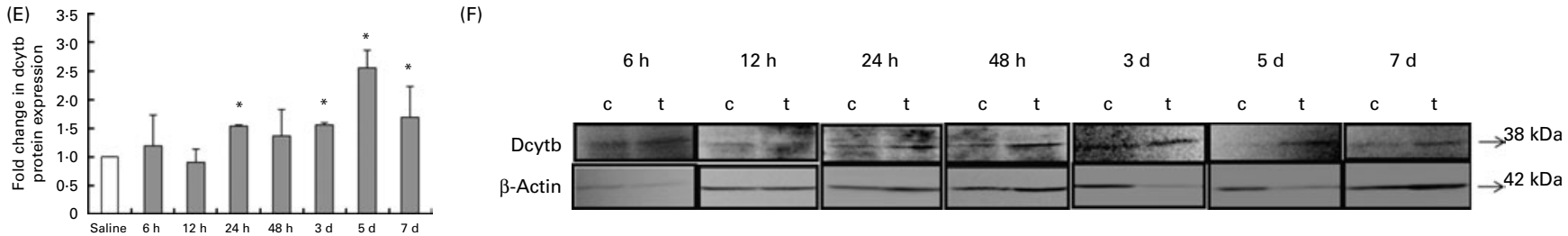

(G)

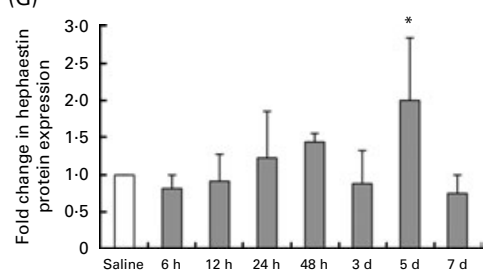

(H)

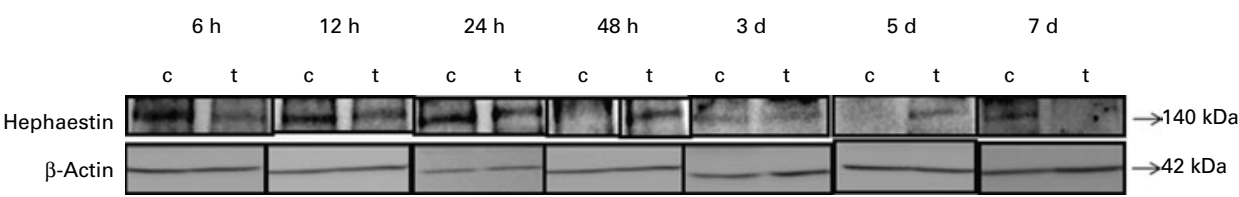

(J)
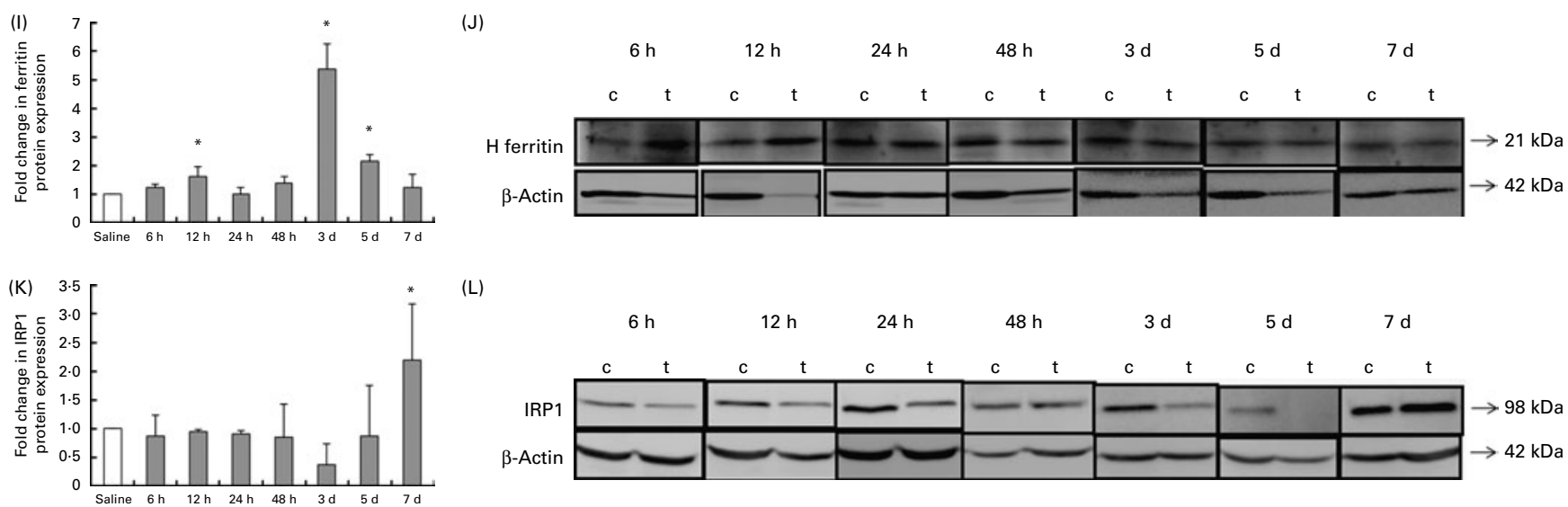

(L)

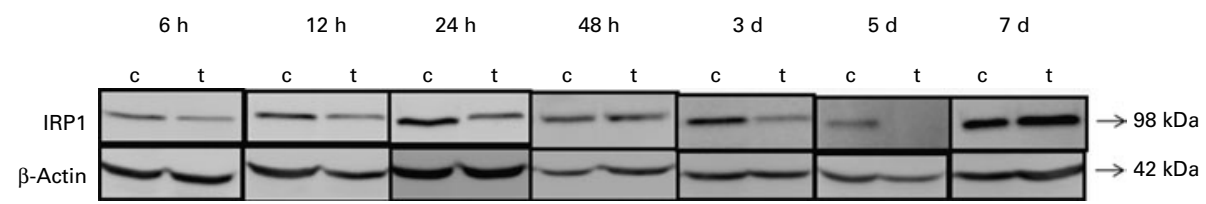

Fig. 2. Effect of acute inflammation on the expression of iron-related proteins in the duodenum. Protein levels of (A) divalent metal transporter 1 (DMT1), (C) ferroportin, (E) duodenal cytochrome b (dcytb), $(G)$ hephaestin, (I) ferritin and (K) iron regulatory protein 1 (IRP1) in acutely inflamed mice, expressed relative to levels in saline ( $\square$ )-treated mice ( $n 3$ at each time point for each protein). (A, C, E, G, I and K) Data from saline-treated mice represent the mean of combined values from all the time periods of the study. The values for saline-treated mice were normalised to 1 , which are shown in the figures. Values are means, with standard deviations represented by vertical bars. * Mean values were significantly different $(P \leq 0.05)$. (B, D, F, H, J and $\mathrm{L})$ Representative blots for each protein for each time period studied. $\square$, Turpentine oil. c, Control; t, test; H, heavy. 
using the same methodology (data not shown), indicating that the protocol used was appropriate and that the expression of TfR1 in the duodenum was too low to be detected. Protein levels of IRP1 were unaffected at most of the time periods studied except for a significant increase on day 7 (Fig. 2(K) and (L)). The findings were similar for IRP2 (data not shown). Resolution of inflammation was associated with attenuation of many of the effects seen. The effects of inflammation on the levels of mRNA for the proteins of interest did not show any consistent pattern (see Fig. S1(A)-(F) of the supplementary material, available online at http://www.journals.cambridge. org/bjn).

\section{Effects of acute inflammation on hepcidin expression in the liver}

In acutely inflamed mice, hepatic hepcidin mRNA expression tended to be higher than that in control mice from $6 \mathrm{~h}$ onwards, with the increases being statistically significant at 3 and $5 \mathrm{~d}$ after the turpentine injection (Fig. 3(A)).

\section{Effects of acute inflammation on serum iron levels}

In acutely inflamed animals, serum Fe levels tended to be lower at the early time periods studied and rose progressively over time to higher levels at the later time points (Fig. 3(B)). However, these changes were not found to be statistically significant.

\section{Effects of chronic inflammation on the proteins of interest} in the duodenum

It was found that protein levels of DMT1 (see Fig. S2(A) and (B) of the supplementary material, available online at http://www. journals.cambridge.org/bjn) and ferroportin did not show any consistent changes in chronically inflamed mice (see Fig. S2(C) and (D) of the supplementary material, available online). Protein levels of dcytb were significantly decreased at weeks 2 and 4 (see Fig. S2(E) and (F) of the supplementary material, available online), while those of hephaestin were significantly lower at week 1 only (see Fig. S2 $(G)$ and $(H)$ of the supplementary material, available online). Ferritin protein expression was significantly higher at 4 weeks (see Fig. S2(I) and (J) of the supplementary material, available online). Protein levels of TfR1 were not detectable by Western blotting. IRP1 expression was initially significantly higher $48 \mathrm{~h}$ after the turpentine injections. This was followed by significant reductions in its levels at 1 and 4 weeks (see Fig. S2(K) and (L) of the supplementary material, available online). There were no significant changes in the levels of IRP2 at any of the time points studied (data not shown). mRNA levels for the various proteins of interest were unaffected in mice except for the increased levels of mRNA for DMT1, ferroportin, dcytb, TfR1 and ferritin at 4 weeks. (see Fig. S3(A)-(F) of the supplementary material, available online). Levels of TfR 1 mRNA, which generally correlate with TfR1 protein, showed an increase at 2 weeks as well.

\section{Effects of chronic inflammation on hepcidin expression in the liver}

In chronically inflamed mice, hepcidin expression was significantly elevated at 2 and 3 weeks after the last turpentine injection (Fig. 4(A)).

\section{Effects of chronic inflammation on serum iron levels}

In chronically inflamed mice, serum Fe levels tended to be lower at the early time points studied but were not significantly different; however, they were significantly higher at week 4 (Fig. 4(B)).

\section{Discussion}

The duodenum is the main site of absorption of dietary $\mathrm{Fe}$ from the gastrointestinal tract. In the present study, the effects of acute and chronic inflammation on the expression of molecules involved in the uptake of non-haem Fe in the duodenum were investigated over the periods that ranged from $6 \mathrm{~h}$ up to 4 weeks of inflammation. In acutely inflamed mice, duodenal ferritin levels were found to be significantly elevated at $12 \mathrm{~h}$ and 3 and $5 \mathrm{~d}$ after the turpentine injection. This suggests accumulation of $\mathrm{Fe}$ in the duodenum in response to the inflammation. The elevations seen in ferritin levels, without significant effects on the expression of hepcidin and ferroportin, are likely to be due to the action of pro-inflammatory cytokines in increasing ferritin expression in cells ${ }^{(12,30)}$. It has been shown that IL- $1 \beta$ enhances ferritin (heavy-chain) expression by binding to $5^{\prime}$ leader sequences present on ferritin (heavy chain) in both

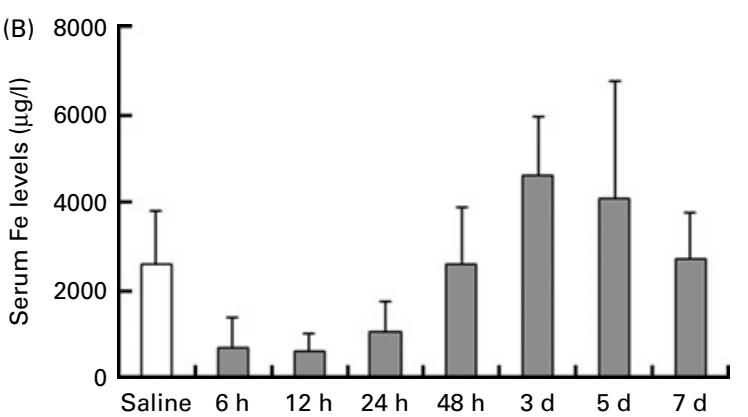

Fig. 3. Effect of acute inflammation on hepatic hepcidin expression and serum iron levels. mRNA expression of $(A)$ hepcidin ( $n$ 3) and (B) serum iron levels $(n 3-5)$ in acutely inflamed and saline ( $\square$ )-treated mice. Values are means, with standard deviations represented by vertical bars. Data from saline-treated mice in each panel represent the mean of combined values from all the time periods of the study. ${ }^{*}$ Mean values were significantly different $(P \leq 0 \cdot 05)$. $\square$, Turpentine oil. 
(A)

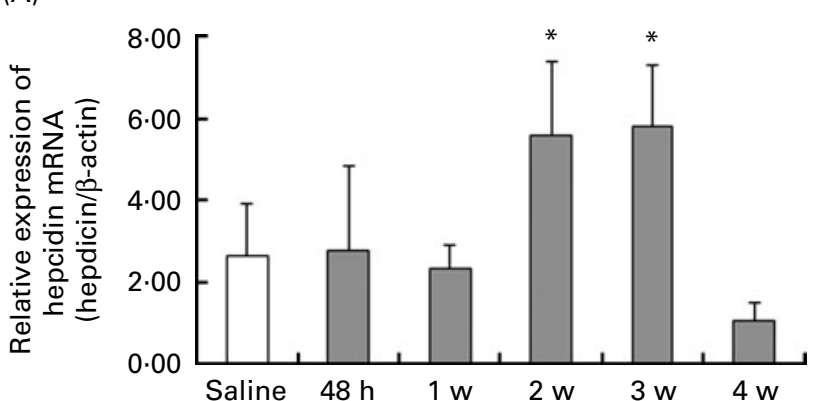

(B)

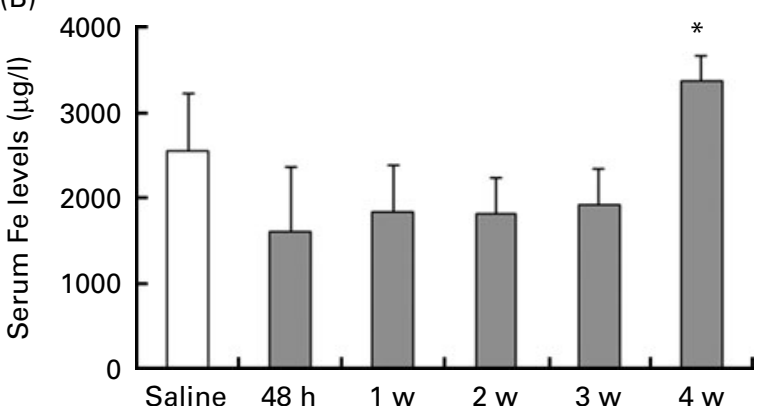

Fig. 4. Effect of chronic inflammation on hepatic hepcidin expression and serum iron levels. mRNA expression of (A) hepcidin ( $n 3$ ) and (B) serum iron levels $(n$ 3-6) in chronically inflamed and saline ( $\square$ )-treated mice. Values are means, with standard deviations represented by vertical bars. Data from saline-treated mice in each panel represent the mean of combined values from all the time periods of the study. ${ }^{*}$ Mean values were significantly different $(P \leq 0 \cdot 05)$. $\square$, Turpentine oil. w, Weeks.

human hepatoma cells (HepG2 cells) and primary human umbilical vein endothelial cells ${ }^{(30)}$. It is likely that such a mechanism may be operational in the present study as well, as various cytokines are known to be elevated in response to turpentine $^{(18)}$. Wessling-Resnick ${ }^{(1)}$ has suggested that the downregulation of ferroportin and the up-regulation of ferritin, during states of inflammatory stress, occur simultaneously to induce Fe retention and sequestration. Such accumulation of Fe in the enterocytes would account for the tendency towards lowered serum Fe levels at the initial time periods, in both acute and chronic models of inflammation in the present study.

Yeh et al. ${ }^{(31)}$ have shown reduced expression of duodenal ferroportin in rats between 12 and $36 \mathrm{~h}$ after administration of lipopolysaccharide and increased expression at $48 \mathrm{~h}$. In the present study, the expression of ferroportin was increased between days 3 and 7, despite elevated levels of serum IL-6 and hepatic hepcidin. This was followed by increased levels of ferritin in the duodenum. We postulate that this is likely to be a response to high levels of Fe accumulating in the enterocytes. Vanoaica et ll $^{(32)}$ have reported that ferritin levels in the enterocytes may have a regulatory role to play in the absorption of dietary Fe. Their work on mice with an intestinal ferritin heavy-chain gene deletion has shown that increases in the free Fe pool in the enterocytes resulted in increases in the expression of ferroportin, even in the presence of an increased induction of hepcidin in the liver. We hypothesise that the increase in the expression of ferroportin seen in the present study was likely to be secondary to the increases in the levels of Fe retained in the enterocytes. Thus, the effect of the increased levels of $\mathrm{Fe}$ in the enterocytes seemed to override that of hepcidin on ferroportin expression. Increased ferroportin expression would result in Fe being exported into the circulation. This probably contributes to the progressive increases seen in serum Fe levels at the later time periods studied, in both acutely and chronically inflamed mice. In such a setting, it would have been useful to determine the serum levels of hepcidin in our models. However, we were unable to measure this in the mice studied due to the non-availability of commercially available reagents for this assay. This is a limitation of the present study, as such information would have enabled us to make a better correlation between the serum levels of hepcidin and its effects on the enterocytes.
The expression of DMT1, which is responsible for entry of Fe from the intestinal lumen, was found to be significantly lower in acutely inflamed mice. We postulate that the decrease in DMT1 expression in these cells is possibly secondary to increased Fe content within the enterocytes and also by hepcidin, as the expression of this protein is known to be regulated by both factors ${ }^{(33-37)}$. The expression of dcytb was found to be significantly increased in response to acute inflammation. The effects on hephaestin expression were less consistent. Sheikh et al. ${ }^{(18)}$, in their study in rats extending up to $24 \mathrm{~h}$ after turpentine injections, have reported both increases and decreases in the expression of dcytb and hephaestin. However, the dose used in their study (10 mg turpentine oil/kg body weight) was much less than that used in the present study ( $4.3 \mathrm{~g}$ turpentine oil $/ \mathrm{kg}$ body weight), and was administered into the limbs of the experimental rats. These differences and the different species used make it difficult to make direct comparisons between the effects seen in these studies. It is possible that there may be other signalling events, involved in the processes of acute inflammation, which influence the expression of these molecules.

The magnitude of the effects seen in the present study was greater in acutely inflamed mice. Fold increases seen in serum levels of IL-6 were higher in acutely inflamed mice than in those with chronic inflammation, and were associated with a higher degree of induction of hepcidin. In the chronic model, hepcidin induction was significantly elevated only at the later time points studied (weeks 2 and 3), despite significant fold increases in serum IL-6 levels at earlier time points. We postulate that this is likely to be due to the lower serum levels of IL-6 in chronically inflamed mice compared with levels in acutely inflamed mice. A previous study using mouse primary hepatocytes has shown that IL- 6 at $20 \mathrm{ng} / \mathrm{ml}$ stimulated hepcidin expression in vitro ${ }^{(38)}$. In the present study, the expression of hepcidin was increased at serum levels of IL-6 that were less than $2 \mathrm{ng} / \mathrm{ml}$ (data not shown). The concentrations of IL-6 in vivo, which the hepatocytes in the present study were exposed to, are not known. Hence, it would be difficult to make accurate correlations with regard to this. It is likely that multiple signalling events may be involved in regulating hepcidin induction during inflammatory stress in vivo. 
The lower degree of induction of hepcidin in the chronic model may account for less marked effects seen in the molecules involved in Fe uptake in these animals. Serum IL-6 levels in these mice were many fold lower than those seen in acutely inflamed mice. Thus, the degree of inflammation appears to influence the magnitude of changes seen. We have previously shown that IL-6 levels in duodenal homogenates from acutely inflamed mice were significantly higher than in those from corresponding control animals at all the time periods studied ${ }^{(39)}$. The lack of significant inflammation in the duodenum (as indicated by the lack of significant elevation of IL-6 levels in tissue homogenates) in chronically inflamed mice, in contrast to what was seen in acutely inflamed mice ${ }^{(39)}$, may also contribute to these observations. The present data thus indicate that high levels of inflammation (both systemic and localised) appear to be necessary to produce significant changes in the proteins involved in $\mathrm{Fe}$ homeostasis. This may explain the improvement seen in AI with attenuation of inflammation ${ }^{(2)}$.

In addition, intestinal epithelial cells undergo constant turnover. Cells from the intestinal crypts migrate to the tip of the villus and are eventually sloughed off. These events usually take place over 1 to $2 \cdot 5 \mathrm{~d}$ in the mouse duodenum ${ }^{(40)}$. Intestinal crypt cells express ferritin but not dcytb, DMT1, ferroportin and hephaestin ${ }^{(41)}$. The expression levels of the latter proteins increase as the crypt cells transit through the middle cells to become mature villus enterocytes. Ferritin levels are thus likely to be affected by inflammation even before full maturation to villus enterocytes, while the changes seen in the expression levels of the other Fe-related proteins in the present study would have occurred in differentiated enterocytes. The turnover time of the intestinal epithelial cells is likely to account for the finding that the effects seen were more marked in acutely inflamed mice than in those which were chronically inflamed. It would also explain why the effects waned with passage of time, as the degree of inflammation decreased. Hence, the turnover of intestinal epithelial cells was likely to have influenced inflammationinduced changes seen in the expression levels of the duodenal proteins of interest in the present study. It thus appears likely that sustained inflammation would be necessary for the effects seen to persist.

In addition to the time points studied, it would also have been useful to study the expression of these proteins between the first and last injections of turpentine that were used to produce the chronic model, as such data may contribute to a better understanding of the interplay between acute and chronic inflammation. We hope to be able to address this issue in a future study.

In human subjects, acute inflammation has been shown to rapidly increase the levels of urinary hepcidin and decrease the levels of serum $\mathrm{Fe}^{(8)}$. However, the expression of Fe-related duodenal proteins involved in Fe absorption has not been studied in this setting. In the present study, acute inflammation resulted in hypoferraemia, which was associated with an increased expression of hepcidin in the liver and ferritin in the duodenum. We postulate that, in response to acute inflammation, similar changes may occur in Fe-related proteins in human subjects as well. Such changes in these proteins would result in decreased $\mathrm{Fe}$ absorption and increased sequestration of Fe within the intestinal cells, which are known to occur in response to inflammation ${ }^{(1)}$.

It must be kept in mind that the number of animals used for the studies in each time period was small ( $n 6$ for mRNA expression studies and $n 3$ for Western blotting). It is possible that changes of small magnitude that may have occurred in the turpentine-treated group may not have been detected because of the small sample sizes in the study.

In conclusion, the present study provides data, over a prolonged time period, on the effects of inflammation on the proteins involved in non-haem Fe uptake in the duodenum. There are very few studies that have investigated such effects over such a wide range of time periods. States of acute and chronic inflammation were found to significantly affect the expression of proteins involved in non-haem $\mathrm{Fe}$ uptake in the duodenum. The overall effects in both states were similar, with acute inflammation producing more marked effects than chronic inflammation. Resolution of inflammation was associated with attenuation of many of these effects. The present data also support the postulate that ferritin levels in enterocytes may have a role to play in regulating duodenal $\mathrm{Fe}$ absorption. The cumulative effect of these alterations are likely to cause decreased absorption of dietary Fe, leading to hypoferraemia and contributing to the development of AI.

\section{Acknowledgements}

The authors would like to thank the Department of Biotechnology, New Delhi, India (grant reference no.: BT/PR5925/ Med/14/716/2005) for financial assistance for the study. The contributions of each author are as follows: A. S. performed the experiments, analysed and interpreted the data, and wrote the manuscript; J. V. was involved in interpreting the data and revising the manuscript; J. T. helped with some of the assays; V. J. and T. M. helped in the statistical analysis; R. J. S. and A. T. M. contributed to conceptualising the study and revising the manuscript; $M$. J. conceptualised and designed the study, analysed and interpreted the data, and revised the manuscript. The authors declare that they have no conflicts of interest.

\section{References}

1. Wessling-Resnick M (2010) Iron homeostasis and the inflammatory response. Annu Rev Nutr 30, 105-122.

2. Weiss G \& Goodnough LT (2005) Anemia of chronic disease. $N$ Engl J Med 352, 1011-1023.

3. Andrews NC (2004) Anemia of inflammation: the cytokinehepcidin link. J Clin Invest 113, 1251-1253.

4. Theurl I, Mattle V, Seifert M, et al. (2006) Dysregulated monocyte iron homeostasis and erythropoietin formation in patients with anemia of chronic disease. Blood 107, 4142-4148.

5. Ganz T (2005) Hepcidin - a regulator of intestinal iron absorption and iron recycling by macrophages. Best Pract Res Clin Haematol 18, 171-182. 
6. Nicolas G, Chauvet C, Viatte L, et al. (2002) The gene encoding the iron regulatory peptide hepcidin is regulated by anemia, hypoxia, and inflammation. J Clin Invest 110, $1037-1044$

7. Nemeth E, Tuttle MS, Powelson J, et al. (2004) Hepcidin regulates cellular iron efflux by binding to ferroportin and inducing its internalization. Science 306, 2090-2093.

8. Nemeth E, Rivera S, Gabayan V, et al. (2004) IL-6 mediates hypoferremia of inflammation by inducing the synthesis of the iron regulatory hormone hepcidin. J Clin Invest 113, $1271-1276$.

9. Oliveira SJ, Pinto JP, Picarote G, et al. (2009) ER stress-inducible factor $\mathrm{CHOP}$ affects the expression of hepcidin by modulating C/EBPalpha activity. PLoS One $\mathbf{4}$, e6618.

10. Vecchi C, Montosi G, Zhang K, et al. (2009) ER stress controls iron metabolism through induction of hepcidin. Science $\mathbf{3 2 5}$, $877-880$.

11. Rogers JT (1996) Ferritin translation by interleukin-1and interleukin-6: the role of sequences upstream of the start codons of the heavy and light subunit genes. Blood $\mathbf{8 7}$, $2525-2537$.

12. Torti SV, Kwak EL, Miller SC, et al. (1988) The molecular cloning and characterization of murine ferritin heavy chain, a tumor necrosis factor-inducible gene. J Biol Chem 263, 12638-12644.

13. Ludwiczek S, Aigner E, Theurl I, et al. (2003) Cytokinemediated regulation of iron transport in human monocytic cells. Blood 101, 4148-4154.

14. Nairz M, Fritsche G, Brunner P, et al. (2008) Interferongamma limits the availability of iron for intramacrophage Salmonella typhimurium. Eur J Immunol 38, 1923-1936.

15. Yang F, Liu XB, Quinones M, et al. (2002) Regulation of reticuloendothelial iron transporter MTP1 (Slc11a3) by inflammation. J Biol Chem 277, 39786-39791.

16. Koening CL, Miller JC, Nelson JM, et al. (2009) Toll-like receptors mediate induction of hepcidin in mice infected with Borrelia burgdorferi. Blood 114, 1913-1918.

17. Pigeon C, Ilyin G, Courselaud B, et al. (2001) A new mouse liver-specific gene, encoding a protein homologous to human antimicrobial peptide hepcidin, is overexpressed during iron overload. J Biol Chem 276, 7811-7819.

18. Sheikh N, Dudas J \& Ramadori G (2007) Changes of gene expression of iron regulatory proteins during turpentine oil-induced acute-phase response in the rat. Lab Invest $\mathbf{8 7}$, $713-725$.

19. Theurl I, Aigner E, Theurl M, et al. (2009) Regulation of iron homeostasis in anemia of chronic disease and iron deficiency anemia: diagnostic and therapeutic implications. Blood 113, 5277-5286.

20. Bhasin G, Kauser H \& Athar M (2002) Iron augments stage-I and stage-II tumor promotion in murine skin. Cancer Lett 183, $113-122$.

21. Bhasin G, Kauser H \& Athar M (2004) Free radical generating agents lead to the rapid progression of benign skin tumors to carcinoma in iron-overloaded mice. Arch Toxicol $\mathbf{7 8}$, $139-146$.

22. Mishra D, Sudarshan M \& Chakraborty A (2003) Elemental alteration, iron overloading and metallothionein induction in experimental hepatocarcinogenesis: a free radicalmediated process? Toxicol Lett 203, 40-47.

23. Dupic F, Fruchon S, Bensaid M, et al. (2002) Duodenal mRNA expression of iron related genes in response to iron loading and iron deficiency in four strains of mice. Gut $\mathbf{5 1}$, 648-653.

24. Ludwiczek S, Theurl I, Artner-Dworzak E, et al. (2004) Duodenal HFE expression and hepcidin levels determine body iron homeostasis: modulation by genetic diversity and dietary iron availability. $J$ Mol Med (Berl) 82, 373-382.

25. Takeuchi K, Bjarnason I, Laftah AH, et al. (2005) Expression of iron absorption genes in mouse large intestine. Scand J Gastroenterol 40, 169-177.

26. Vokurka M, Krijt J, Sulc K, et al. (2006) Hepcidin mRNA levels in mouse liver respond to inhibition of erythropoiesis. Physiol Res 55, 667-674.

27. Canonne-Hergaux F, Gruenheid S, Ponka P, et al. (1999) Cellular and subcellular localization of the Nramp2 iron transporter in the intestinal brush border and regulation by dietary iron. Blood 93, 4406-4417.

28. Lowry OH, Rosebrough NJ, Farr AL, et al. (1951) Protein measurement with the Folin phenol reagent. I Biol Chem 193, 265-275.

29. Kohyama M, Ise W, Edelson BT, et al. (2009) Role for Spi-C in the development of red pulp macrophages and splenic iron homeostasis. Nature 457, 318-321.

30. Rogers JT, Bridges KR, Durmowicz GP, et al. (1990) Translational control during the acute phase response. Ferritin synthesis in response to interleukin-1. J Biol Chem 265, 14572-14578.

31. Yeh KY, Yeh M \& Glass J (2004) Hepcidin regulation of ferroportin 1 expression in the liver and intestine of the rat. $\mathrm{Am}$ J Physiol Gastrointest Liver Physiol 286, G385-G394.

32. Vanoaica L, Darshan D, Richman L, et al. (2010) Intestinal ferritin $\mathrm{H}$ is required for an accurate control of iron absorption. Cell Metab 12, 273-282.

33. Brasse-Lagnel C, Karim Z, Letteron P, et al. (2011) Intestinal DMT1 cotransporter is down-regulated by hepcidin via proteasome internalization and degradation. Gastroenterology 140, 1261e1-1271e1.

34. Frazer DM, Wilkins SJ, Becker EM, et al. (2003) A rapid decrease in the expression of DMT1 and Dcytb but not Ireg1 or hephaestin explains the mucosal block phenomenon of iron absorption. Gut 52, 340-346.

35. Frazer DM, Wilkins SJ, Becker EM, et al. (2002) Hepcidin expression inversely correlates with the expression of duodenal iron transporters and iron absorption in rats. Gastroenterology 123, 835-844.

36. McKie AT, Barrow D, Latunde-Dada GO, et al. (2001) An iron-regulated ferric reductase associated with the absorption of dietary iron. Science 291, 1755-1759.

37. Zoller H, Koch RO, Theurl I, et al. (2001) Expression of the duodenal iron transporters divalent-metal transporter 1 and ferroportin 1 in iron deficiency and iron overload. Gastroenterology 120, 1412-1419.

38. Lee P, Peng H, Gelbart T, et al. (2006) Regulation of hepcidin transcription by interleukin-1 and interleukin-6. Proc Natl Acad Sci U S A 102, 1906-1910.

39. Faith M, Sukumaran A, Pulimood AB, et al. (2008) How reliable an indicator of inflammation is myeloperoxidase activity? Clin Chim Acta 396, 23-25.

40. Creamer B, Shorter RG \& Bamforth J (1961) The turnover and shedding of epithelial cells. I. The turnover in the gastro-intestinal tract. Gut 2, 110-118.

41. Roy CN \& Enns CA (2000) Iron homeostasis: new tales from the crypt. Blood 96, 4020-4027. 